\title{
CLINICAL PROFILE AND MANAGEMENT OF LIVER ABSCESS (AMOEBIC AND NON-AMOEBIC) AND COMPARISON BETWEEN CONSERVATIVE MANAGEMENT AND PIGTAIL CATHETERISATION IN NORTH-CENTRAL INDIA
}

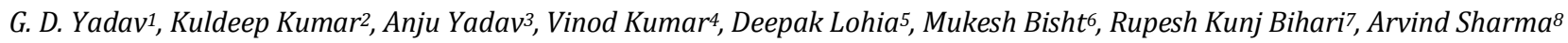

${ }^{1}$ Associate Professor, Department of General Surgery, GSVM Medical College, Kanpur.

${ }^{2}$ Assistant Professor, Department of General Surgery, Rama Medical College, Kanpur.

${ }^{3}$ Sr. Divisional Medical Officer, Department of Paediatrics, North Central Railway, Kanpur.

4 Junior Resident, Department of General Surgery, GSVM Medical College, Kanpur.

5 Senior Resident, Department of General Surgery, GSVM Medical College, Kanpur.

${ }^{6}$ Senior Resident, Department of General Surgery, GSVM Medical College, Kanpur.

${ }^{7}$ Senior Resident, Department of General Surgery, GSVM Medical College, Kanpur.

8Junior Resident, Department of General Surgery, GSVM Medical College, Kanpur.

\section{ABSTRACT}

\section{BACKGROUND}

Liver abscess is a common and major health problem in the lower socio-economic group. It can be managed with drugs, ultrasoundguided needle aspiration and open surgical drainage. The aim of the study was to assess the variation in clinical presentation in liver abscesses and to study the therapeutic efficacy of conservative management and ultrasound-guided pigtail drainage of liver abscess and to compare the two modalities of treatment of liver abscess.

\section{MATERIALS AND METHODS}

The study was conducted in the GSVM Medical College and Associated LLR Hospital Kanpur and Rama Medical College Kanpur from December 2010 to October 2014 among 224 patients (Case Group), out of which 100 cases (study group) were selected for comparing the two modalities of treatment of uncomplicated LA (Liver Abscess). Study by convenient allocation since the duration of the study was few months. The patients were selected by convenience allocation technique. The sample size estimation was also done at conveniences. The treatment modalities to be compared included conservative management versus ultrasound-guided pigtail drainage of LA measuring between 6.0 and $10.0 \mathrm{~cm}$ in the maximum diameter.

\section{RESULTS}

In the study group, there was history of alcohol intake in 63/100 cases (63\%) and most of the patients belonged to the lower socioeconomic status and of these $49 \%$ were unskilled labourers. The mean value of serum bilirubin in Group 1 was $0.92 \pm 0.14$ $\mathrm{mg} / \mathrm{dL}$, whereas in Group 2 was $0.95 \pm 0.14 \mathrm{mg} / \mathrm{dL}$. The mean value of serum ALP in study Group 1 was $310 \pm 67.49 \mathrm{IU} / \mathrm{L}$ and in Group 2 was $373.5 \pm 88.29 \mathrm{IU} / \mathrm{L}$.

\section{CONCLUSION}

Liver abscess, a dreadful disease of a time can be very well managed these days if uncomplicated. Either by conservative therapy or an ultrasonographically guided pigtail catheterisation with better result and quicker healing rates, quicker reduction in TLC count, faster improvement in symptoms \{decrease in VAS (visual analogue score)\} with USG-guided method, although a longer stay in the hospital but overall a better option than conservative management for larger abscess cavities.

\section{KEYWORDS}

Liver Abscess, Conservative Management, Pigtail Catheterisation, North Central India Lower Socio-Economic Group.

HOW TO CITE THIS ARTICLE: Yadav GD, Kumar K, Yadav A, et al. Clinical profile and management of liver abscess (amoebic and non-amoebic) and comparison between conservative management and pigtail catheterisation in north-central India. J. Evolution Med. Dent. Sci. 2017;6(95):6935-6939, DOI: 10.14260/jemds/2017/1505

\section{BACKGROUND}

A liver abscess is an infectious, space-occupying and pus-filled cavity within the liver. Origin may be pyogenic, amoebic or fungal or mixed infection.

The two most common abscesses being pyogenic and amoebic. Its severity depends on the source of the infection and the underlying condition of the patient.

'Financial or Other Competing Interest': None.

Submission 14-11-2017, Peer Review 08-12-2017,

Acceptance 14-12-2017, Published 23-12-2017.

Corresponding Author:

Dr. Anju Yadav

\#3/1596, HIG,

Avas Vikas Ambedkar Puram,

Kalyanpur, Kanpur-208017, U. P.

E-mail: anjuyadavk1@gmail.com

DOI: $10.14260 /$ jemds $/ 2017 / 1505$
Most common bacterial causes are Escherichia coli, Klebsiella spp., Proteus, Staphylococcus aureus and Streptococcus faecalis. Streptococcus milleri and anaerobes such as Bacteroides spp. are increasingly common.

Amoebic liver abscesses (LA) are common in tropical regions, mainly where 'Entamoeba histolytica' is endemic and is more prevalent in individuals (mostly young males) with suppressed cell-mediated immunity. In both the types of hepatic abscesses, right lobe of the liver is the most likely site or infection.

Heavy alcohol consumption ( $>150$ gm per day) is another common finding in patient population with LA.1,2

The clinical presentation of both the types may be elusive with combination of fever, right upper quadrant pain and hepatomegaly with or without jaundice. 


\section{Four Groups of Treatment Modalities are Effective-}

1. Drug therapy only.

2. USG-guided aspiration and drug.

3. Percutaneous catheter drainage and drug.

4. Laparotomy, drainage and drug.

Conservative treatment in the form of metronidazole/ tinidazole and sometimes combining it with antibiotic in associated secondary infection is the sheet anchor in the management of around $80 \%$ of LA. Drainage is only required in large abscesses having compression features, secondary infection and resistance to drug therapy. Percutaneous catheter drainage is a viable option to drain the high viscous content of LA adequately. Relieving of symptoms is the parameter for the response of treatment. Surgical intervention in all cases is unwanted and it should be avoided.

\section{Surgical Intervention}

Open Surgical Drainage is rarely indicated and may be i.e. required in the Setting 3

- Large abscesses with poor yield on needle aspiration or percutaneous drainage.

- Clinical deterioration despite attempted needle aspiration.

- Complicated LA (like ruptured abscess in peritoneal cavity with features of peritonitis).

- Complicated LA (ruptured in the pleural cavity/pericardial cavity/adjacent viscera).

Mortality is low with LA compared with PLA. Abscesses are slow to resolve.

\section{MATERIALS AND METHODS}

\section{Study Design}

Non-randomised controlled trial and convenient allocation was done. The study was conducted in the Department of General Surgery and Radiodiagnosis, GSVM Medical College and Associated LLR Hospital and Rama Medical College, Kanpur from December 2010 to October 2014 on patients who were admitted from casualty and outpatient department with a diagnosis of liver abscess. Data was compiled using Microsoft Excel and analysed using SPPS 20.0. Categorical variable for analysis using percentages and chi-square test to tailed ' $\mathrm{p}$ ' value $<0.05$ was considered significant.

The diagnosis of LA was based on history of anorexia, malaise, fever and pain abdomen with or without a preceding history of diarrhoea and findings of tender hepatomegaly, leucocytosis and ultrasound evidence of amoebic liver abscess. On this basis, a total of 224 cases of LA were admitted; of these 100 patients were identified as the study group for the purpose of thesis. Thus, the following two groups were identified.

\section{Study Group I}

These patients were treated with antiamoebic (metronidazole) and antibiotic (ciprofloxacin) drugs.

\section{Study Group II}

These patients were treated by ultrasound-guided indwelling pigtail catheter drainage in addition to antiamoebic (metronidazole) and antibiotic (ciprofloxacin) drugs.

\section{Inclusion Criteria}

Patient with abscess size ranging from $6.0 \mathrm{~cm}$ till $10.0 \mathrm{~cm}$ was included.

\section{Exclusion Criteria}

Solitary left lobe liver abscess, impending rupture, ruptured abscess, jaundice, organised abscess and abscess in close proximity to large vascular structures in liver.

For statistical analysis, we used paired/ unpaired ' $t$ ' test and testing the significance within the group and between the groups.

\section{Methodology}

The patients in the study group were subjected to a detailed history (including alcoholism), complete general medical and physical examination. Specific investigations like complete haemogram, liver function test, coagulation profile (PT/ INR), ultrasound abdomen, chest $\mathrm{x}$-ray, microscopic examination and culture of aspirated pus (Group II).

The patients were examined daily for clinical improvement. Improvement in pain (VAS), fever, anorexia and hepatomegaly within 72 hours of institution of therapy was considered the criteria for continuing that particular modality of treatment.

Selected patients were randomly divided into 2 groups of 50 each, of which patients in Study Group II were subjected to ultrasound-guided pigtail catheterisation after taking informed consent. Output was collected and sent for microscopic examination of wet mount for trophozoites of Entamoeba histolytica, Gram's staining, pus culture and sensitivity. Catheter output charting was done daily and a chart was maintained.

Outcome was assessed by abdominal pain as quantified, fever, resolution of liver abscess ultrasonographically, TLC count, length of hospital stay or any complication.

At 72 hours, patient's outcome was again assessed. If they had not responded to the first modality of treatment, the patient was subjected to second modality of treatment i.e. conservative converted to open drainage.

\section{RESULTS}

This study of 100 patients with mean age of patients in group 1 as 38.24 years (range: 18 - 67 years), whereas in Group 2 as 39.24 years (range: 18 - 67 years). There was statistically no significant difference between the mean of two age groups with a male: female ratio as 19: 1 .

In the study group, there was history of alcohol intake in $63 / 100$ cases (63\%) and most of the patients belonged to the lower socioeconomic status and of these $49 \%$ were unskilled labourers. The mean value of serum bilirubin in Group 1 was $0.92 \pm 0.14 \mathrm{mg} / \mathrm{dL}$, whereas in Group 2 was $0.95 \pm 0.14 \mathrm{mg} / \mathrm{dL}$. The mean value of serum ALP in study Group 1 was $310 \pm$ 67.49 IU/L and in Group 2 was $373.5 \pm 88.29 \mathrm{IU} / \mathrm{L}$.

The mean value of TLC at admission in Group 1 was 15504 cells $/ \mathrm{mm}^{3}\left(6800-34200\right.$ cells $\left./ \mathrm{mm}^{3}\right)$ and in group 2 was 15426 cells $/ \mathrm{mm}^{3}\left(7000-34200\right.$ cells $\left./ \mathrm{mm}^{3}\right)$. The mean of the maximum diameter of the liver abscess in Group 1 was $7.5 \mathrm{~cm}$ with a range of 6.4 to $9.2 \mathrm{~cm}$. The mean of the maximum diameter in the study Group 2 was $7.93 \mathrm{~cm}$ with a range of 6.2 to $9.6 \mathrm{~cm}$. 
The mean value of TLC at 72 hours in Group 1 was 9512 cells $/ \mathrm{mm}^{3}$ (4600 - 18600 cells $/ \mathrm{mm}^{3}$ ) and in Group 2 was 7142 cells $/ \mathrm{mm}^{3}$ (4100- 13800 cells $/ \mathrm{mm}^{3}$ ).

The mean score of pain was 4.76 in study Group 1 patients, while in study Group 2 patients it was 4.92 at admission. There was no significant difference between the two groups $(\mathrm{p}>0.05)$.

\begin{tabular}{|c|c|c|}
\hline VAS in Study Group 1 & At Admission & At 72 Hrs. \\
\hline $0-2$ & 3 & 35 \\
\hline $3-5$ & 31 & 12 \\
\hline $6-8$ & 16 & 3 \\
\hline $9-10$ & 0 & 0 \\
\hline
\end{tabular}

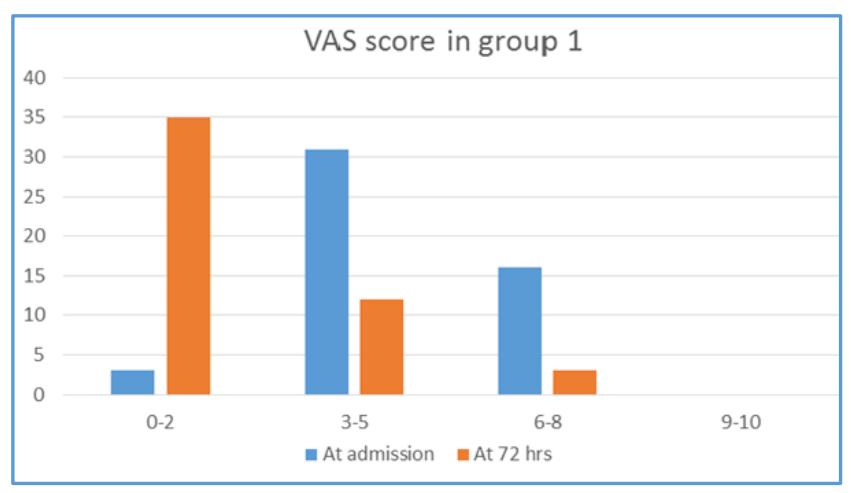

\begin{tabular}{|c|c|c|}
\hline VAS in Study Group 2 & At Admission & At 72 Hrs. \\
\hline $0-2$ & 2 & 42 \\
\hline $3-5$ & 29 & 8 \\
\hline $6-8$ & 19 & 0 \\
\hline $9-10$ & 0 & 0 \\
\hline
\end{tabular}

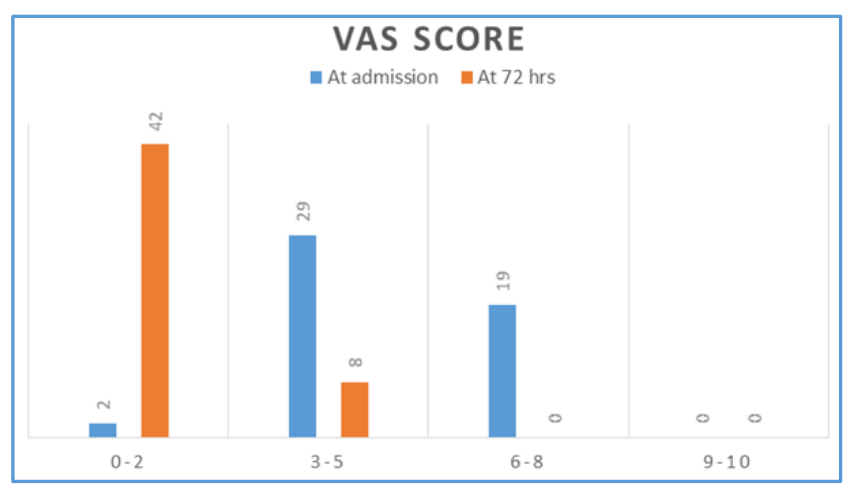

In Group 2 patients, the mean VAS score at $72 \mathrm{hrs}$. was 1.82, whereas in Group 1 was 2.32. There is a significant difference between the two groups $(\mathrm{p}<0.05)$.

The volume of pus drained immediately on insertion of the pigtail catheter ranged from 130 to $490 \mathrm{~mL}$ with a mean of $244.4 \mathrm{~mL}$. During the subsequent 72 hours, the amount of pus drained ranged from $110 \mathrm{~mL}$ to $400 \mathrm{~mL}$ with a mean of 183 $\mathrm{mL}$. The total amount of pus drained from the LA from the time of insertion till 72 hours later ranged from $250 \mathrm{~mL}-830 \mathrm{~mL}$.

Three $(n=3)$ cases were shifted from study Group 1 to study Group 2 with pigtail catheterisation drainage due to increase in pain scoring at $72 \mathrm{hrs}$. No decrease in TLC value and no change/ increase in size of LA on ultrasound.

\begin{tabular}{|c|c|c|c|}
\hline Parameters & Group 1 & Group 2 & P value \\
\hline $\begin{array}{c}\text { Age (Mean } \pm \text { SD) } \\
\text { Years }\end{array}$ & $\begin{array}{c}38.34 \pm \\
11.09\end{array}$ & $\begin{array}{c}39.24 \pm \\
12.33\end{array}$ & \\
\hline $\mathrm{M}: \mathrm{F}$ & $45: 5$ & $50: 0$ & \\
\hline $\begin{array}{l}\text { Alcohol Consumption } \\
\text { (Yes/No) }\end{array}$ & $32 / 18$ & $31 / 19$ & \\
\hline Sr. Bilirubin (mg/dL) & $\begin{array}{c}0.92 \pm \\
0.14\end{array}$ & $\begin{array}{c}0.95 \pm \\
0.14\end{array}$ & 0.2866 \\
\hline S. ALP (IU/L) & $\begin{array}{l}310 \pm \\
67.49\end{array}$ & $\begin{array}{c}373.5 \pm \\
88.29\end{array}$ & 0.0001062 \\
\hline $\begin{array}{c}\text { Size (In } \mathrm{cm} \text {, according } \\
\text { to USG) }\end{array}$ & $7.5 \pm 0.66$ & $\begin{array}{c}7.93 \pm \\
0.95 \\
\end{array}$ & 0.009957 \\
\hline TLC (A) (cells $/ \mathrm{mm}^{3}$ ) & $\begin{array}{c}15504 \pm \\
6582\end{array}$ & $\begin{array}{c}15426 \pm \\
6092\end{array}$ & 0.9511 \\
\hline TLC (72 hrs.) & $\begin{array}{c}9512 \pm \\
3749 \\
\end{array}$ & $\begin{array}{l}7142 \pm \\
2115 \\
\end{array}$ & 0.00018606 \\
\hline VAS (A) & $\begin{array}{c}4.76 \pm \\
1.41 \\
\end{array}$ & $\begin{array}{c}4.92 \pm \\
1.41 \\
\end{array}$ & 0.5718 \\
\hline VAS (72 hrs.) & $\begin{array}{c}2.32 \pm \\
1.24 \\
\end{array}$ & $\begin{array}{c}1.82 \pm \\
0.74 \\
\end{array}$ & 0.01613 \\
\hline Stay (Days) & $\begin{array}{l}5.06 \pm \\
3.09 \\
\end{array}$ & $\begin{array}{c}9.38 \pm \\
1.98 \\
\end{array}$ & 0.0000001 \\
\hline $\begin{array}{c}\text { Aspirate } \\
\text { (On Insertion) (mL) }\end{array}$ & & $\begin{array}{c}244.4 \pm \\
88.6 \\
\end{array}$ & \\
\hline Aspirate (72 hrs.) & & $183 \pm 63.1$ & \\
\hline Aspirate (Total) & & $\begin{array}{l}426 \pm \\
108.4\end{array}$ & \\
\hline
\end{tabular}

\section{DISCUSSION}

In our study, the mean age of the patients was 38.74 years (range 18 to 67 years) with maximum number $(n=17)$ of patients were in the age group of 31 to 40 years (40\%). LA has been reported mostly in the 20 to 40 years' age group. $4,5,6$ There are differing reports from various studies. The mean age of patients of LA before 1966 was reported as 47 years. In 1978, however, a report showed change in mean age of patient's presentation to be 30 years (range from 1 to 60 years). ${ }^{7}$ Similarly, another study conducted between 1979 - 81 reported maximum number of cases were between the age group of 31 to 45 years. ${ }^{5}$ Between $1981-86$, the age of the patients was reported to vary from 14 years to 65 years with over $70 \%$ cases occurring between $2^{\text {nd }}$ to $4^{\text {th }}$ decade of life. ${ }^{3}$ In 1999, change in mean age of presentation of LA was reported from 31.4 years to 33.3 years over a period of 20 years. The change was not significant.

The male: female ratio in the study group was 19: 1 commensurate with reports in literature of a male preponderance in a ratio ranging from 10.1 to $17: 1.13,4$ (Table 2). A retrospective analysis in 1978 reported that the male: female ratio was 7.66: 1 , which had remained constant over 30 years (1946 - 1976). These studies reflect increase in the maleto-female ratio over the last 50 years. Our study also reflects the high male-to-female discrepancy. The increased ratio may be due to the fact that the patients in our study belonged to the lower socioeconomic status and there was a high percentage of alcohol intake in the patients.

The history of alcohol intake was positive in the study group $(n=100)$. The alcohol intake was positive in $63 / 100$ cases $(63 \%)$. A positive history of alcoholism was obtained by Waring in $67.5 \%$ of 40 cases, by Rogers in $54.5 \%$ of 44 cases, by Megaw in $70 \%$ of 170 cases and by Chen and his associates in $67.7 \%$ of 31 cases. Peiris reported it in $24 \%$ of 28 cases. Thus, the incidence of alcohol intake in our study is reportedly the same as reported in literature. Excessive alcohol intake 
makes the liver more prone to developing LA and is also responsible for the larger size of the abscess, greater frequency of complications and higher mortality. ${ }^{3}$ Alcohol lowers the body resistance, suppresses liver function and is accompanied by malnutrition. All factors making the person, especially of the lower socio-economic status more prone to develop LA. ${ }^{3}$ However, there is no major study that has quantified the alcohol intake or reported the duration of alcohol consumption and so the incidence of alcohol consumption seen in cases of LA differs in different studies according to the environment, tradition and socioeconomic status of the patients under study.

The disease was predominantly seen in people from low socioeconomic status. Poor socioeconomic status had been considered a risk factor for this disease. Earlier studies had also reported the same. ${ }^{8,9,3}$ The lower socioeconomic status leads poor sanitation and hygiene and sub-optimal sewer system all of which factors facilitate ingestion of E. histolytica cysts.

The mean value of total serum bilirubin in Case Group was $0.8 \mathrm{mg} / \mathrm{dL}$. The mean value in Study Group I was $0.92 \mathrm{mg} / \mathrm{dL}$ and in Study Group II was $0.95 \mathrm{mg} / \mathrm{dL}$. None of the patients in the study group had jaundice. The mean value of $1.9 \mathrm{mg} / \mathrm{dL}$ for total bilirubin had been reported in earlier study. Another study had reported 46 cases (31.94\%) of jaundice out of 144 cases of amoebic liver abscess. ${ }^{6}$ Another study had reported the bilirubin level of $>3.5 \mathrm{mg} / \mathrm{dL}$, was associated with worse prognosis. ${ }^{4}$

Jaundice occurs because of intrahepatic obstruction or associated hepatitis and is usually seen in large or multiple abscesses; abscess situated at porta hepatis is more likely to produce jaundice because of extra-hepatic obstruction.

The mean value of serum alkaline phosphatase ALP in study Group 1, the mean value was $310 \mathrm{IU} / \mathrm{L}$ and in Study Group II it was 373 IU/L. Earlier reports showed raised ALP in $76 \%$ cases of amoebic liver abscess. ${ }^{6}$ (High ALP levels may be seen in $60 \%-80 \%$ cases of amoebic liver abscess. Thus, ALP is the most reliable and consistent biochemical indicator of amoebic liver abscess. The rise is usually 2 - 4 times. Most liver function tests are of no value in the diagnosis of amoebic liver abscess, except significantly raised serum ALP with normal serum alanine transaminase and serum arginine transaminase. The average ALP level had been reported to be $24 \mathrm{KA}$ units. It returned to normal after resolution of the abscess.

The mean TLC at admission in Study Group I was 15504 cells $/ \mathrm{mm}^{3}$ (6800 - 34200 cells $/ \mathrm{mm}^{3}$ ), and in Group 2 was 15426 cells $/ \mathrm{mm}^{3}$ (7000 - 34200 cells $\left./ \mathrm{mm}^{3}\right)$. Earlier studies had reported the mean TLC to be $15000 \mathrm{cell} / \mathrm{mm} 3$ with the range 7500 cells $/ \mathrm{mm}$ to 25000 cells $/ \mathrm{mm}^{3}$. Others had reported mean TLC to be 19100 cells $/ \mathrm{mm}^{3}$. Thus, in the present study, at 72 hours the change in TLC was found significant in both the study groups $(\mathrm{p}<0.05)$.

The mean of the maximum diameter in Study Group I was $7.5 \mathrm{~cm}$ (range 6.4 to $9.2 \mathrm{~cm}$ ) and in Study Group II it was 7.93 $\mathrm{cm}$ (range 6.2 to $9.6 \mathrm{~cm}$ ). Earlier studies had reported the mean value of largest diameter to be $7.0 \mathrm{~cm}$.

Patients in the study group were evaluated by visual analog scoring of pain at admission and at $72 \mathrm{hrs}$. The change in VAS in response to conservative management in Study Group I and in Study Group II in response to pigtail drainage was significant. There was statistically significant difference in the VAS of pain with patients responding better to pigtail drainage. Three patients in Study Group I was shifted to pigtail drainage due to increase in VAS at 72 hours.

In the present study, three cases $(6 \%)$ were shifted from Study Group I to Study Group II with pigtail catheter drainage due to increase if pain scoring at $72 \mathrm{hrs}$. $(\mathrm{n}=3)$, persistence of fever $(n=3)$, no decrease in TLC values $(n=3)$ and no change/increasing size of LA on ultrasound $(n=2)$. All patients with the initial insertion of pigtail catheter improved and did not require change in the modality of treatment.

The present study undertook to compare the efficacy of the two modalities of treatment, viz. medical treatment versus pigtail insertion for LA measuring 6.0 to $10.0 \mathrm{~cm}$. There was not much difference in size of LA in the two groups under study. Further, our study showed that the abscesses of size between $6.0 \mathrm{~cm}$ and $10.0 \mathrm{~cm}$ could be taken for pigtail catheter drainage at presentation, as the time of resolution was more rapid in Group II as compared to Study Group I.

In the Study Group II, the volume of pus drained immediately on pigtail insertion ranged from 130 to $490 \mathrm{~mL}$ with a mean of $244.4 \mathrm{~mL}$. During the subsequent 72 hours, the amount of pus drained ranged from $110 \mathrm{~mL}$ to $400 \mathrm{~mL}$ with a mean of $183 \mathrm{~mL}$. The total amount of pus drained from the LA from the time of insertion till $72 \mathrm{hrs}$. later ranged from $250 \mathrm{~mL}$ - $830 \mathrm{~mL}$. In a review of literature, an author reported that the total amount of pus drained ranged from 120 to $2500 \mathrm{~mL}$ with an average of $787 \mathrm{~mL} .{ }^{10}$ Another study had reported that the volume of pus aspirated till the healing of abscess cavity ranged from $150 \mathrm{~mL}$ to $4350 \mathrm{~mL}$. In contrast, there was no change in size of abscesses treated by conservative method alone at the same point of time. ${ }^{11}$

There was statistically significant difference in the change in size of liver abscess at $72 \mathrm{hrs}$. between the two modalities of treatment $[p<0.05]$. This suggests better response in cases of pigtail drainage. In one study, the pigtail drainage was reported to have marked resolution of liver abscess. When it was considered to be successful, ultrasound was suggestive of total resolution or reduction of size to $<3 \mathrm{~cm} .{ }^{10}$

Resolution of liver abscess was seen more in our studies in Study Group II patients as compared to Study Group I patients. There had been reports that showed that only $30 \%$ of liver abscesses resolved completely within 6 months and that the abscess cavity may persist for as long as 2 years. ${ }^{12}$ The average time taken by pigtail catheter for reduction of the abscess cavity to $50 \%$ of its original size was 5 days. ${ }^{13}$ While the complete resolution of abscess cavity had been reported to be 26 weeks (mean 15 weeks). ${ }^{14}$ The resolution of LA had been reported to take time up to 23 months (mean 7 months) by medical therapy alone. While the other study had reported complete resolution in only 3 out of 44 patients $(6.8 \%)$ after medical therapy. 4 In our study, there was no complete resolution of amoebic liver abscess in both the study groups. However, the reduction in size and volume of abscess cavity was marked and occurred earlier in Study Group II cases.

In the Study Group II, the abscess was considered resolved on the basis of ultrasound findings at the time of pigtail catheter removal when the size of abscess was found to be markedly deceased. The period ranged from 4 to 42 days with the mean of 15.6 days. The average catheter duration required was 7 days in earlier studies, all of whom had large abscess cavities (mean volume $432 \mathrm{~mL}$ ). ${ }^{15}$ In other study, the range of 
catheter duration was 6 to 38 days with an average of 14 days. ${ }^{10}$

Mean duration of hospital stay in Group I was 5.06 days and in Group II was 9.38 days. There is statistically significant difference between Group I and Group II ( $p<0.01)$. The total mean duration of hospital stay was 7.22 in the study group. Earlier studies had reported the range of hospital stay to be 4 - 24 days. ${ }^{13}$ Another study had reported mean hospital stay of 7.3 days of patients treated by conservative method. ${ }^{14}$

Thus, our study clearly proves that the resolution of uncomplicated solitary right lobe amoebic liver abscess measuring between 6.0 and $10.0 \mathrm{~cm}$, was faster and earlier if the LA was drained with a pigtail catheter than in patients who were managed conservatively. Abscesses less than $6.0 \mathrm{~cm}$ can be managed with medical treatment alone.

\section{Limitation of the Study}

Due to short duration of study, convenience allocation technique was followed. Thus, sampling size was also calculated by convenience. The results of the study cannot be generalised due to the potential bias resulting from the allocation technique and sample size estimation.

\section{CONCLUSION}

Liver abscess, a dreadful disease of a time can be very well managed these days, if uncomplicated. Either by conservative therapy or an ultrasonographically guided pigtail catheterisation with better result and quicker healing rates, quicker reduction in TLC count, faster improvement in symptoms (decrease in VAS score) with USG-guided method, although a longer stay in the hospital but overall a better option than conservative management for larger abscess cavities.

\section{REFERENCES}

[1] Saleem MM. Amoebic liver abscess-a cause of acute respiratory distress in an infant: a case report. J Med Case Rep 2009;3:46.

[2] Wells CD, Arguedas M. Amoebic liver abscess. South Med J 2004;97(7):673-82.
[3] Hai AA, Singh A, Mittal VK, et al. Amoebic liver abscess. Review of 220 cases. Int Surg 1991;76(2):81-3.

[4] McKaigney C. Hepatic abscess: case report and review. West J Emerg Med 2013;14(2):154-7.

[5] Liver abscesses and hydatid disease. BMJ 2001;322:537.

[6] Khanna S, Chaudhary D, Kumar A, et al. Experience with aspiration in cases of amoebic liver abscess in an endemic area. Eur J Clin Microbiol Infect Dis 2005;24(6):428-30.

[7] Tan YM, Chung AY, Chow PK, et al. An appraisal of surgical and percutaneous drainage for pyogenic liver abscesses larger than $5 \mathrm{~cm}$. Ann Surg 2005;241(3):48590.

[8] Petri WA, Singh U. Diagnosis and management of amebiasis. Clin Infect Dis 1999;29(5):1117-25.

[9] Salles JM, Moraes LA, Salles MC. Hepatic amebiasis. Braz J Infect Dis 2003;7(2):96-110.

[10] Kapadia S, Duttaroy D, Ghodgaonkar P, et al. Percutaneous catheter drainage of liver abscesses. Indian J Surg 2002;64(6):516-9.

[11] Blessmann J, Binh HD, Hung DM, et al. Treatment of amoebic liver abscess with metronidazole alone or in combination with ultrasound guided needle aspiration: a comparative, prospective, and randomized study. Trop Med Int Health 2003;8(11):1030-4.

[12] Seeto RK, Rockery DC. Amebic liver abscess: epidemiology, clinical features, and outcome. West J Med 1999;170(2):104-9.

[13] Rajak CL, Gupta S, Jain S, et al. Percutaneous treatment of liver abscesses: needle aspiration versus catheter drainage. Am J Roentqenol 1998;170(4):1035-9.

[14] Ghosh S, Sharma S, Gadpayle AK, et al. Clinical, laboratory, and management profile in patients of liver abscess from northern India. J Trop Med 2014;2014:142382.

[15] Takeuchi T, Okuzawa E, Nozaki T, et al. High seropositivity of Japanese homosexual men for amebic infection. J Infect Dis 1989;159(4):808. 